\title{
Influence of Disc Specimen Configuration on Its Three-Dimensional Dynamic Stress Balance
}

\author{
Sheng Zhang, ${ }^{1}$ Bingxin Yu ${ }^{D},{ }^{1}$ Xiaojun Li, ${ }^{1}$ Longfei Wang, ${ }^{2}$ and Xulong Zhang ${ }^{1}$ \\ ${ }^{1}$ School of Energy Science and Engineering, Collaborative Innovation Center of Coal Work Safety, Henan Polytechnic University, \\ Jiaozuo Henan 454001, China \\ ${ }^{2}$ School of Civil Engineering, Chongqing University, Chongqing 400045, China
}

Correspondence should be addressed to Bingxin Yu; yubingxinhpu@126.com

Received 14 August 2020; Revised 11 November 2020; Accepted 6 December 2020; Published 23 December 2020

Academic Editor: Zhijie Wen

Copyright (C) 2020 Sheng Zhang et al. This is an open access article distributed under the Creative Commons Attribution License, which permits unrestricted use, distribution, and reproduction in any medium, provided the original work is properly cited.

In order to investigate the dynamic stress balance of different configurations of rock specimens, three-dimensional finite element models of SHPB were established. Five types of configuration disc specimens with a diameter of $75 \mathrm{~mm}$ and a thickness of $30 \mathrm{~mm}$ were impacted at a speed of $5 \mathrm{~m} / \mathrm{s}$ using a special-shaped bullet. The propagation laws of stress wave on the contact surface of the specimen-bar and the inside of the specimen were analyzed, and the time history of the stress balance factors at different positions of the specimen was obtained. The results show that the amplitudes of the transmitted waves corresponding to the five types of disc specimens with different configurations have obvious differences, and the stress propagation in the specimen has three-dimensional characteristics. According to the ease of achieving stress balance, the five configuration specimens are ordered by notched semicircular bending disc, flattened Brazilian disc, cracked straight-through flattened Brazilian disc, Brazilian disc, and cracked straight-through Brazilian disc specimen. Among them, only the first three configurations of the specimen reached the stress balance. The dynamic stress balance is affected by the disc loading mode, end contact conditions, the presence of prefabricated cracks, and disc thickness. In addition, as the disc loading end is a processed platform, it is beneficial to achieve stress balance. Prefabricated cracks are not conducive to achieving stress balance. The loading method of the notched semicircular bending disc is more conducive to achieving stress balance. This research has a certain guiding significance for selecting suitable specimen configuration and research methods to carry out rock dynamic fracture experiments.

\section{Introduction}

With the gradual increase in coal mining depth, the stress level of coal and rock mass increases accordingly, geological conditions such as gas and hydrology have become more complex [1-3], and dynamic disasters such as rock bursts, rock bursts, and mining disturbances have become more prominent [4-6]. The importance of research on dynamic fracture characteristics of rock masses has become increasingly prominent. To understand the dynamic failure mechanism of rock, it is first necessary to accurately determine the lithologic parameters associated with rock dynamic failure. At present, the Split Hopkinson Pressure Bar (SHPB) experiment has been widely used in the study of dynamic performance parameters of various materials $[7,8]$. Its effectiveness is based on the assumption of "onedimensional propagation of stress waves" and "uniform stress of test specimens" [9]. Disc specimens of various configurations were used to test the dynamic mechanical properties of the rock, including Brazilian disc (BD) $[10,11]$, flattened Brazilian disc (FBD) [12], cracked straight-through Brazilian disc (CSTBD) [13, 14], cracked straight-through flattened Brazilian disc (CSTFBD) [15, 16], holed-cracked flattened Brazilian disc (HCFBD) [17], cracked chevron notched Brazilian disc (CCNBD) $[18,19]$, notched semicircular bending disc (NSCBD) [20-22], and cracked chevron notched semicircular bend disc (CCNSCBD) $[23,24]$. Due to the heterogeneity and brittleness of rock materials, the stress uniformity assumption of SHPB experiments is challenged [25]. 
Man and Zhou [26] pointed out that for nonideal materials, nonideal sizes, and nonideal configuration specimens, the two assumptions of "one-dimensionality" and "stress balance" should be satisfied. When these two assumptions are satisfied, the parameters such as dynamic compressive strength and tensile strength obtained by the quasistatic method are meaningful. Rock materials have been destroyed under very small strains. Under such small deformations, in order to obtain accurate experimental data, the wave oscillation caused by the dispersion effect and the stress balance in the specimen must be considered. Conventional SHPB devices have not been able to meet the experimental requirements well; in order to better ensure the two assumptions of the SHPB experiment, some waveform shapers made with various materials and sizes $[10,16,19,27]$ and specialshaped bullets [28-30] have been applied to dynamic test research. The geometry of the disc does not satisfy the onedimensional property. It is worthwhile to study whether the specimen can reach the stress balance before the failure in the dynamic splitting experiment. Ping et al. [31] conducted a SHPB experiment with $50 \mathrm{~mm}$ diameter sandstone $\mathrm{BD}$ specimens and obtained a trapezoidal stress wave with a rising edge of about $50 \mu \mathrm{s}$, which was considered to be able to achieve stress balance before the specimen is destroyed. Li et al. [32] applied experimental and numerical simulation methods to show that the stress balance can be achieved inside the FBD with a diameter of $50 \mathrm{~mm}$, but severe stress unevenness occurs at both ends of the specimen. And the larger the diameter of the specimen, the more severe the stress unevenness. Zhang et al. [33] established a finite element model of a HCFBD with a diameter of $80 \mathrm{~mm}$. The stress balance factor was used to prove that the stress distribution in the specimen was severely uneven and the stress balance could not be reached. Wang et al. [34] considered that small-sized specimens are easier to achieve stress balance and can be treated using a quasistatic method, but for largesized CSTFBD specimens, the quasistatic method will no longer be applicable.

The classic "three-wave method" has been widely used to verify the stress balance of the specimen. The superimposed value of the incident wave and the reflected wave coincides with the transmitted wave, that is, the specimen is considered to be in a stress equilibrium state. Based on this, Yin et al. [35] used the improved SHPB system to perform dynamic and static coupling loading on $50 \mathrm{~mm}$ diameter CSTBD granite specimens and finally achieved stress balance. Dai et al. [36] proved through experiments that the waveform shaper has a great influence on the stress balance of the specimen, and the composite material shaper is used to achieve the stress balance of the semicircular bending disc (SCBD) specimen. Zhang and Zhao [37] applied a conical bullet to the NSCBD specimen with a radius of $25 \mathrm{~mm}$ to obtain a half-sinusoidal stress wave, which proved that the specimen was in a stress equilibrium state before it fractured.

In theory, it seems reasonable to judge the stress balance of the specimen according to the length of the rising edge of the stress wave. However, due to the complexity of stress propagation during the loading of disc specimens [38] and the heterogeneity of rock specimens [39], the accuracy of this method is worth to deliberate. The classical threewave method indirectly judges the stress balance of the specimen based on the stress wave on the pressure bar, ignoring the influence of stress non-one-dimensional propagation in the specimen [26], which simplifies the problem. However, some errors are inevitable when dealing with the wave head, and the degree of coincidence of the final stress wave curve cannot quantify the degree of stress balance of the specimen. In addition, the contact area between the disc specimen and the pressure bar is small, and severe stress concentration occurs at the end of the specimen, and the two-dimensional effect produced is not negligible [40], therefore, this indirect method does not necessarily prove the true balance of the specimen. The numerical simulation method can directly extract the stress history at both ends of the specimen, and the stress balance factor can be used to more accurately measure the stress balance of the specimen. However, in the numerical simulation discussed above, only the specimen model was established, ignoring the influence of contact, and the two-dimensional model ignored the influence of thickness [41]. It is necessary to carry out the analysis of the three-dimensional full-bar model; otherwise, the results obtained may be quite different from the real situation, so the method of numerical simulation needs further study.

In summary, the effectiveness of axially loaded SHPB experiments on cylindrical specimens has been widely recognized. However, there is still controversy about the stress balance of the radial specimen loading SHPB test of the disc specimen. And there is no uniform standard in the configuration and size of the specimen. The three-dimensional finite element SHPB model was established by the numerical simulation method. The dynamic stress distribution characteristics and dynamic stress balance factor history of the disc specimens were analyzed. The influences of the configuration parameters of five types of disc specimens on the dynamic stress balance were studied. The research has certain guiding significance for SHPB testing of rock specimens with special structure.

\section{Stress Wave Propagation and Stress Balance of the Specimen}

2.1. Propagation of Stress Waves on the Pressure Bar. The SHPB experimental device diagram is shown in Figure 1. The bullet impacts the incident bar at a certain speed and generates a stress wave in the incident bar. The incident wave is reflected and transmitted at the contact surface of the incident bar and the specimen, and the contact surface between the specimen and the transmission bar. After the stress wave is reflected back and forth in the specimen multiple times, the stress balance state is reached [9].

In the test, the strain gauge " 1 " on the incident bar recorded the incident wave strain signal $\varepsilon_{\mathrm{i}}(t)$ and the reflected wave strain signal $\varepsilon_{\mathrm{r}}(t)$, and the strain gauge " 2 " on the transmission bar recorded the transmitted wave strain 




FIgURE 1: SHPB system schematic.

signal. The stress at the incident end of the specimen is $\sigma_{1}(t)$ and the stress at the transmitting end is $\sigma_{2}(t)$.

$$
\begin{aligned}
& \sigma_{1}(t)=\frac{E_{B} A_{B}}{A_{S}}\left[\varepsilon_{i}(t)+\varepsilon_{r}(t)\right], \\
& \sigma_{2}(t)=\frac{E_{B} A_{B}}{A_{S}} \varepsilon_{t}(t),
\end{aligned}
$$

where $E_{B}$ is the elastic modulus of the pressure bar, $A_{B}$ is the cross-sectional area of the pressure bar, and $A_{S}$ is the area of the contact surface between the test piece and the pressure bar. If $\sigma_{1}(t)=\sigma_{2}(t)$, that is, the stress at both ends of the specimen is equal, and the specimen is considered to have reached the stress balance.

With a conventional cylindrical bullet impact, an approximately rectangular stress wave can be generated on the incident bar, and the rising edge of the waveform is extremely short, accompanied by wave head oscillation and dispersion effects. However, the tensile strength of the rock is low and the strain at break is small, so it is difficult for the rectangular stress wave to achieve the stress balance before the rock specimen is destroyed. Christensen et al. [42] argue that when the stress-strain behavior of rock materials is studied in the SHPB system, the ideal input stress pulse should be a slope rather than a steep trapezoidal pulse. Luo and Gong [43] used the rectangular wave, triangular wave, and half-sine wave to impact the specimen. By comparison, the half-sine wave can relatively eliminate the stress dispersion phenomenon. In view of this, according to the improved SHPB system proposed by ISRM [44], the model is used to generate a semisinusoidal stress wave by using a special-shaped bullet impact to eliminate the influence of the dispersion effect on the pressure bar.

2.2. Application of Disc Specimens. In order to facilitate the measurement of dynamic tensile strength, fracture toughness and other mechanical parameters of rock, lots of disc specimens of various configurations have been applied to SHPB experiments. However, there is still no relevant research on whether the disc specimens with different configurations can satisfy the stress balance and the degree of stress balance.

Consider the five types of disc specimens, as shown in Table 1, the diameter of the specimen is $d=75 \mathrm{~mm}$, the thickness is $B=30 \mathrm{~mm}$, the platform loading angle is $\alpha=20^{\circ}$, the prefabricated crack length is $a=32 \mathrm{~mm}$, the crack width is 0 , and the distance between the two bearing ends of the NSCBD specimen is $l=55 \mathrm{~mm}$. Under the same experimental conditions, the stress balances were analyzed.

2.3. Calculation Method of Dynamic Stress Balance Factor of Disc Specimens. The stress balance factor, the dimensionless stress difference at both ends of the specimen, has been defined and widely used [29, 33, 45-47]. It quantifies the stress balance of the specimen during dynamic impact. In the finite element model, the stress of the element in the symmetrical position of the specimen at a certain moment is extracted, and the stress balance factor value at this time can be obtained by substituting into the formula (3).

$$
\alpha_{k}=\left|\frac{2\left(\sigma_{\mathrm{SI}}-\sigma_{\mathrm{ST}}\right)}{\sigma_{\mathrm{SI}}+\sigma_{\mathrm{ST}}}\right| .
$$

In formula (3), $\alpha_{k}$ is the stress balance factor, $\sigma_{\mathrm{SI}}$ is the stress at the incident end of the specimen, and $\sigma_{\mathrm{ST}}$ is the stress at the transmission end of the specimen. With the change of time, the stress at both ends of the specimen changes continuously, and the stress balance factor is also in a dynamic process. When $\alpha_{k}$ is less than or equal to 0.05 [48], the specimen is considered to have reached a stress equilibrium state.

\section{3D Full-Bar Model Establishment}

Using the LS-DYNA module in the finite element software ANSYS, a three-dimensional full-bar model of SHPB with a diameter of $100 \mathrm{~mm}$ is established, as shown in Figure 2. The length of the incident bar and the transmission bar is both $2.6 \mathrm{~m}$, the diameter of the specimen is $d=75 \mathrm{~mm}$, and the thickness is $B=30 \mathrm{~mm}$. The bullet has a diameter of $100 \mathrm{~mm}$ and a length of $800 \mathrm{~mm}$, as shown in Figure 3. Due to the symmetry of the model, in order to improve the calculation efficiency, the disc specimen is loaded with a $1 / 4$ model, and the NSCBD specimen is loaded with a $1 / 2$ model.

In the model, the bullet and the pressure bar are the same kind of steel material, and the sandstone with homogeneity is selected. The specific material parameters are shown in Table 2. According to formula (4), the propagation velocity of the stress wave in the pressure bar and the specimen can 
TABLe 1: Application of five configuration discs.

\begin{tabular}{|c|c|c|c|}
\hline Specimen name & Abbreviation & Configuration & Related parameters \\
\hline Brazilian disc & $\mathrm{BD}$ & & $d=75 \mathrm{~mm}$ \\
\hline Flattened Brazilian disc & FBD & & $\begin{array}{c}d=75 \mathrm{~mm} \\
\alpha=20^{\circ}\end{array}$ \\
\hline Cracked straight-through Brazilian disc & CSTBD & & $\begin{aligned} d & =75 \mathrm{~mm} \\
a & =32 \mathrm{~mm}\end{aligned}$ \\
\hline Cracked straight-through flattened Brazilian disc & CSTFBD & & $\begin{array}{c}d=75 \mathrm{~mm} \\
\alpha=20^{\circ} \\
a=32 \mathrm{~mm}\end{array}$ \\
\hline Notched semicircular bending disc & NSCBD & & $\begin{aligned} d & =75 \mathrm{~mm} \\
a & =32 \mathrm{~mm} \\
l & =55 \mathrm{~mm}\end{aligned}$ \\
\hline
\end{tabular}

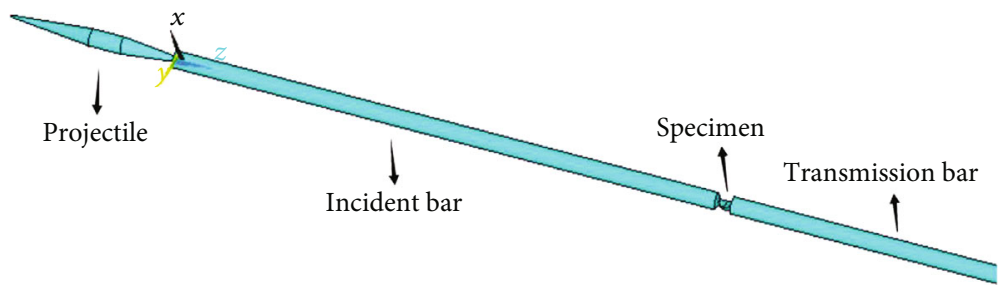

Figure 2: SHPB three-dimensional full-bar model.

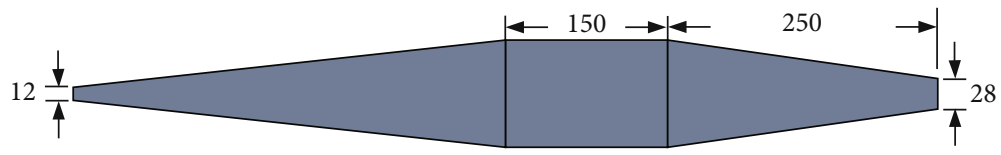

FIGURE 3: Schematic diagram of a special-shaped bullet (unit: $\mathrm{mm}$ ).

TABLE 2: Model parameter table.

\begin{tabular}{lccc}
\hline & Density $\left(\mathrm{kg} / \mathrm{m}^{3}\right)$ & Elastic modulus $(\mathrm{GPa})$ & Poisson's ratio \\
\hline Pressure bar and bullet & 7850 & 210 & 0.30 \\
Specimen & 2730 & 16.3 & 0.28 \\
\hline
\end{tabular}




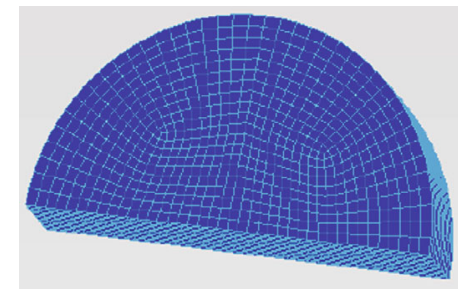

(a) $\mathrm{BD}$

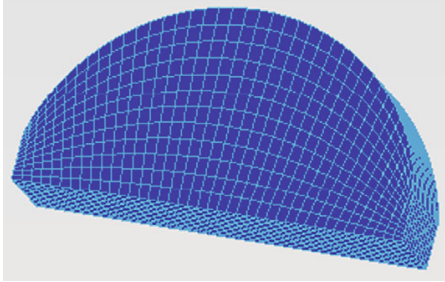

(b) FBD

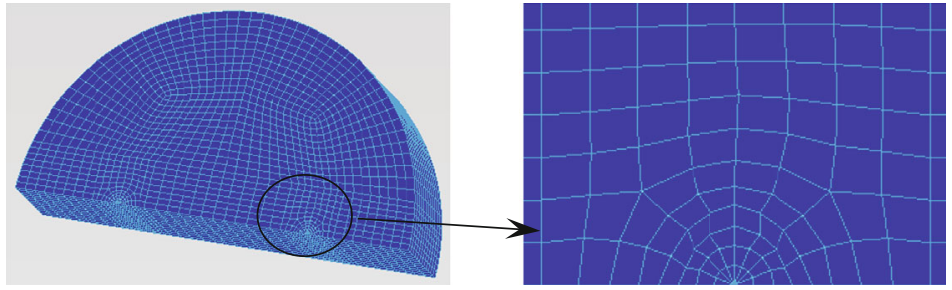

(c) CSTBD (left), crack tip area grid (right)

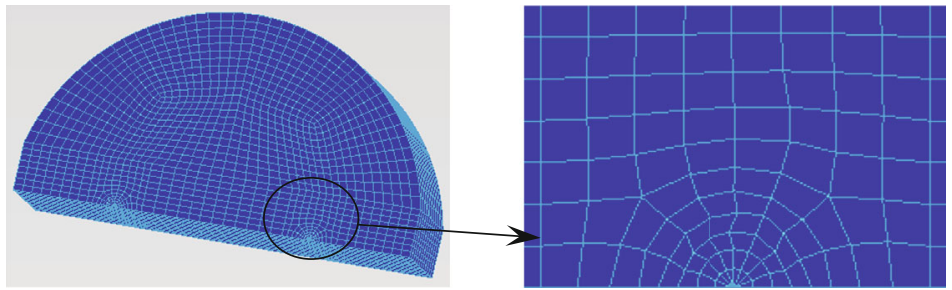

(d) CSTFBD (left), crack tip area grid (right)
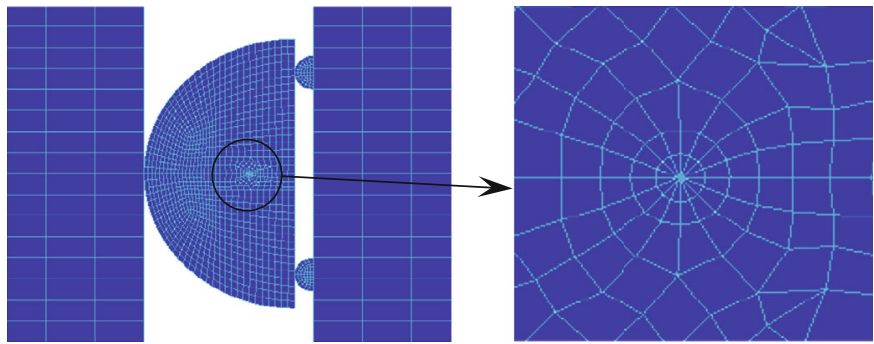

(e) NSCBD (left), crack tip area grid (right)

FIGURE 4: Five configuration specimen models.

be calculated as $5172.2 \mathrm{~m} / \mathrm{s}$ and $2443.5 \mathrm{~m} / \mathrm{s}$, respectively. From the formula (5), the specimen-bar wave impedance ratio $\beta$ is about $1 / 6$. Where $C_{0}$ is the propagation velocity of the wave in the medium.

$$
\begin{gathered}
C_{0}=\sqrt{\frac{E}{\rho}}, \\
\beta=\frac{\left(\rho C_{0}\right)_{S}}{\left(\rho C_{0}\right)_{B}} .
\end{gathered}
$$

The solid 164 eight-node hexahedral element is used to facilitate the propagation of stress waves. The bullet and the strut are divided by a mapping method, and the meshing of the specimen is performed by a sweeping division technique. As shown in Figures 4(a)-4(e) are BD, FBD, CSTBD, CSTFBD, and NSCBD, respectively. The crack tip uses a quarter-node singular element technique and encrypts the unit.

\section{Distribution of Stress Wave on the Pressure Bar and Specimen}

4.1. Stress Wave Analysis on the Pressure Bar. The bullet impacts the incident bar at a speed of $5 \mathrm{~m} / \mathrm{s}$, and a stress wave with a wavelength of about $454 \mu$ s is obtained on the pressure bar. In order to avoid the superposition of the stress waves at the end of the pressure bar, the cross-section center unit is selected on the incident bar and the transmission bar at a distance of $1.4 \mathrm{~m}$ from the loading end of the specimen, respectively. The stress waveforms on the comparison bar are shown in Figures 5 and 6.

It can be seen from Figure 5 that the different specimen configurations have the same incident wave and can reach $200 \mu$ s when rising. The reflected wave showed a slight difference due to the influence of the configuration of the specimen. This difference depends on the contact area of the incident bar with the specimen. The three specimens of $\mathrm{BD}$, CSTBD, and NSCBD have the same contact with the incident bar and are only one line, and the reflected waves are almost 


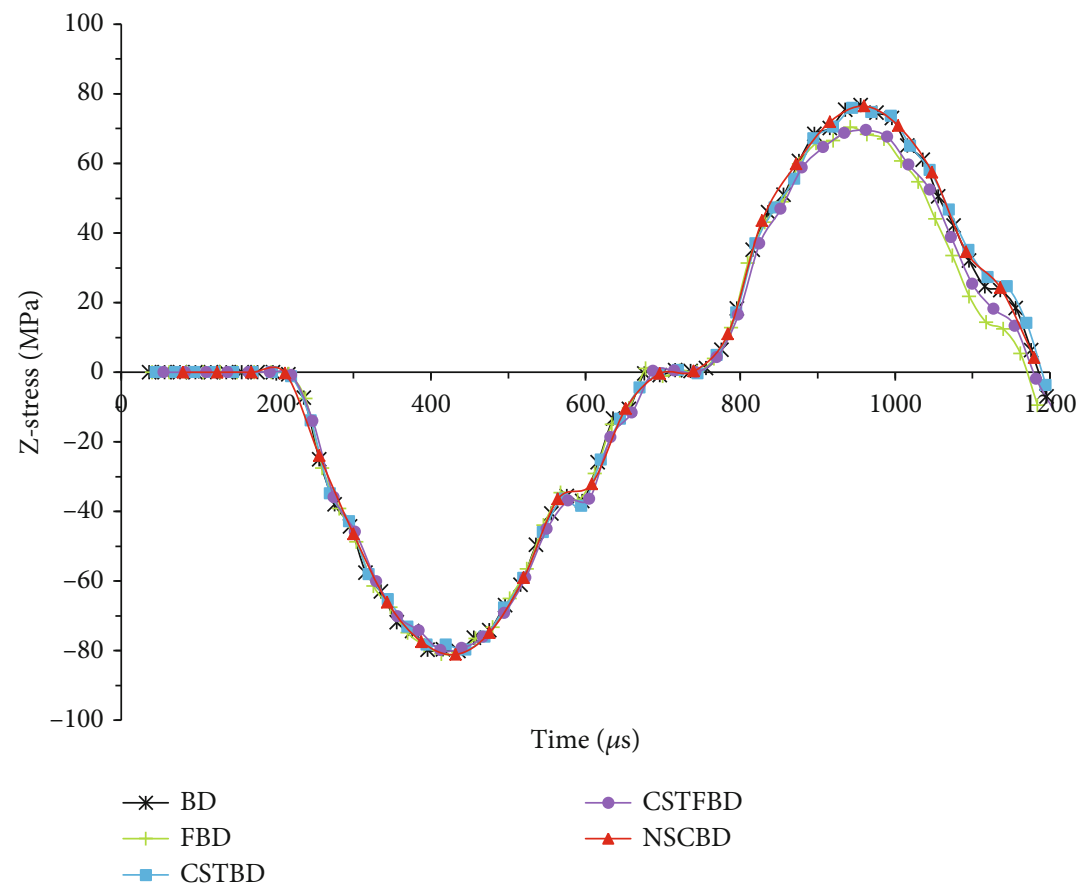

FIgURE 5: Stress waveforms on the incident bar of different models.

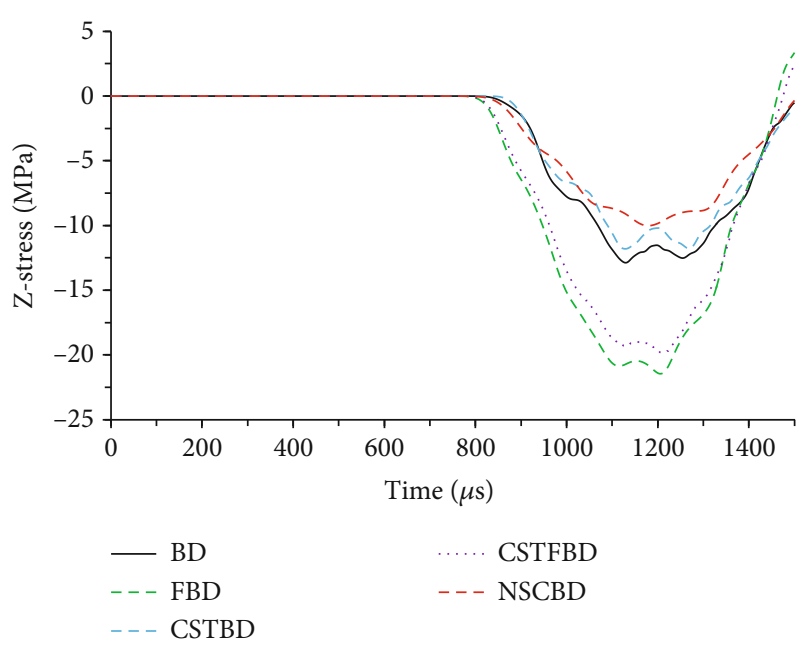

FIgURE 6: Stress waveform on the transmission bar in different models.

identical. The contact between the FBD and CSTFBD specimen and the incident bar is flat. In the process of transmission and reflection, the proportion of reflected waves is relatively small, so the peaks of reflected waves in these two models are smaller than those of the other three configurations.

The stress waves measured on the transmission bars of the five models were shown in Figure 6. The transmitted wave amplitudes of the BD, FBD, CSTBD, CSTFBD, and NSCBD models are $0.154,0.263,0.147,0.247$, and 0.12 times of the incident wave, respectively. When analyzing the transmission waveform, it is necessary to consider not only the transmission of the stress wave between the pressure bar and the specimen but also the propagation of the stress wave in the specimen. The contact surface between the FBD or CSTFBD specimen and the pressure bar is large. In the process of transmission and reflection on the contact surface, the transmission wave ratio is relatively large, so the transmission wave peaks in these two models are higher than those of the other three configurations. The CSTFBD specimen contains prefabricated cracks. When the stress wave propagates to the crack tip in the specimen, partial dissipation and scattering occur, resulting in the stress wave finally propagating to the transmission bar is smaller than the FBD model. The comparison between the BD model and the CSTBD model has the same pattern. For the special loading method of the NSCBD semidisc specimen, since the stress gradually decreases from the center to the edge in the direction perpendicular to the loading diameter, and the bearing end of the specimen is near the edge of the specimen, the transmission wave peak is the smallest. Since the stress gradually decreases from the center to the edge in the direction perpendicular to the loading diameter, and the bearing end of the NSCBD specimen is near the edge of the specimen, the transmission wave peak is the smallest.

4.2. Stress Distribution Characteristics of the Specimen. From the generation of the stress wave to the incoming specimen, it takes $504 \mu \mathrm{s}$, and the stress wave passes from the incoming specimen to the outgoing specimen for $\tau=32 \mu \mathrm{s}$. The variation of stress distribution on different configurations of specimens under impact loading conditions is as follows.

For the BD model, when the stress wave is transmitted into the specimen, the stress distribution in the specimen is seriously asymmetrical, as shown in Figure $7(\mathrm{a})$; the stress distribution in the specimen tends to be symmetrical until $658 \mu \mathrm{s}$, as shown in Figure $7(\mathrm{~b})$; but for less than $10 \mu \mathrm{s}$, this 


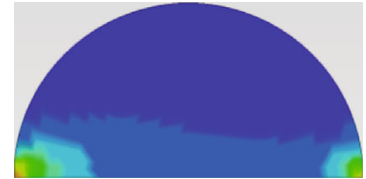

(a) $640 \mu \mathrm{s}$

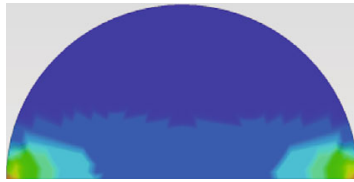

(b) $658 \mu \mathrm{s}$

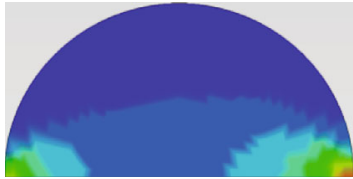

(c) $688 \mu \mathrm{s}$

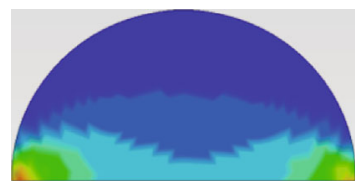

(d) $770 \mu \mathrm{s}$

Figure 7: Stress distribution in BD specimens at different times.

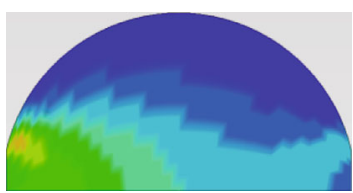

(a) $558 \mu \mathrm{s}$

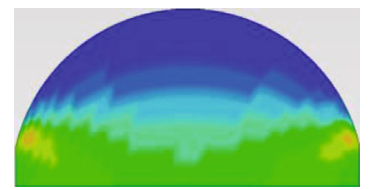

(b) $590 \mu \mathrm{s}$

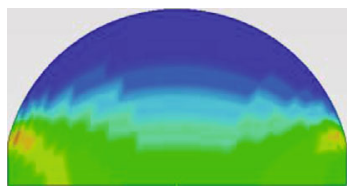

(c) $660 \mu \mathrm{s}$

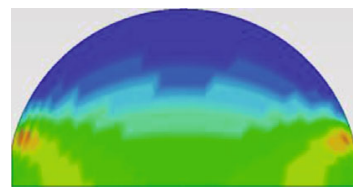

(d) $688 \mu \mathrm{s}$

FIGURE 8: Stress distribution in FBD specimens at different times.



(a) $630 \mu \mathrm{s}$

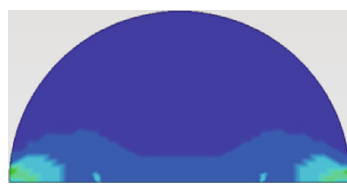

(b) $648 \mu \mathrm{s}$

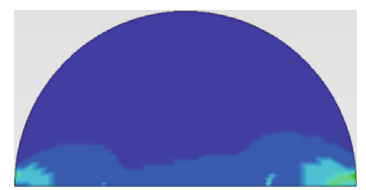

(c) $660 \mu \mathrm{s}$

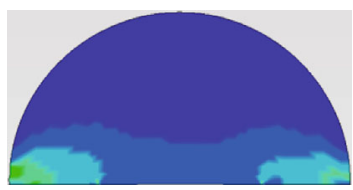

(d) $790 \mu \mathrm{s}$

FIgure 9: Stress distribution in CSTBD specimens at different times.

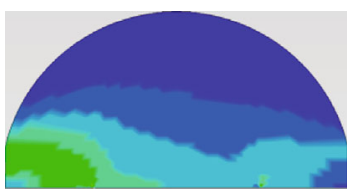

(a) $565 \mu \mathrm{s}$

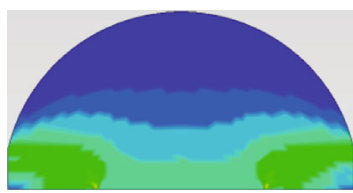

(b) $590 \mu \mathrm{s}$

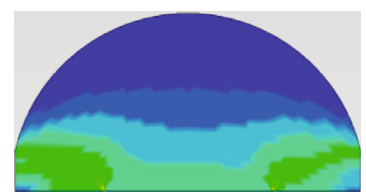

(c) $660 \mu \mathrm{s}$

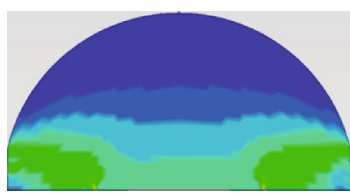

(d) $710 \mu \mathrm{s}$

FIgURE 10: Stress distribution in CSTFBD specimens at different times.

state of stress is broken, as shown in Figure $7(\mathrm{c})$; in the subsequent dynamic process of stress, from $744 \mu \mathrm{s}$ to $812 \mu \mathrm{s}$, the internal stress distribution of the specimen is relatively symmetrical, the internal stress distribution of the specimen is relatively symmetrical, but the end stress difference is obvious, as shown in Figure $7(\mathrm{~d})$. During the whole loading process, the stress in the specimen was mainly distributed in the vicinity of the loaded diameter ligament [33], and stress concentration occurred at both ends of the specimen.

For the FBD model, after the stress wave propagates for $86 \mu \mathrm{s}$ in the specimen, the stress distribution in the specimen tends to be uniform, as shown in Figure 8(b). At a later time, the change in stress distribution is relatively stable. During the entire loading process, the stress distribution in the specimen is significantly more uniform than the BD model. However, the stress in the vicinity of the loaded ligament is higher than that at the edge of the specimen, and the stress concentration phenomenon occurs at the joint between the platform and the arc part of the specimen.
The stress distribution at different times in the CSTBD specimen is shown in Figure 9. At $648 \mu \mathrm{s}$, the stress in the specimen tends to be symmetric, as shown in Figure 9(b). But then the stress distribution turns into an unstable state. Overall, the stress distribution in the specimen is mainly concentrated in the vicinity of the loading diameter ligament. Influenced by prefabricated cracks, the stress distribution above the crack tip is hunchback. Stress concentration occurs at the crack tip, and the stress concentration at the end of the specimen is weakened compared with the BD model.

During the loading process, the stress wave propagates back and forth in the CSTFBD specimen, and the stress distribution in the specimen is relatively uniform at $590 \mu \mathrm{s}$, as shown in Figure 10(b), and then the stress distribution changes little. The stress distribution pattern of the whole process is similar to that of the FBD specimen. The main difference is that the stress concentration phenomenon occurs at the crack tip position, and the stress concentration at the end of the specimen is weakened, as shown in Figure 10. 


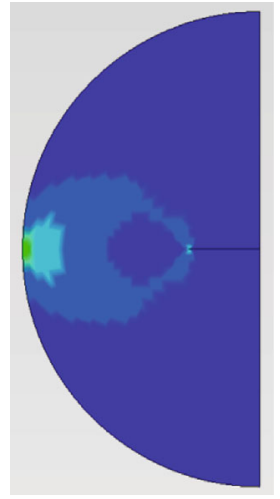

(a) $580 \mu \mathrm{s}$

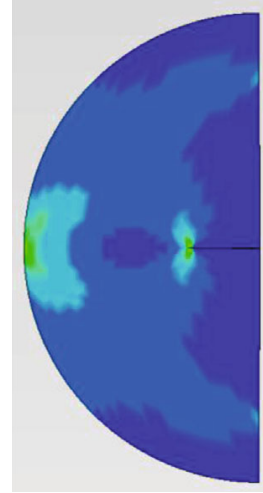

(b) $612 \mu \mathrm{s}$

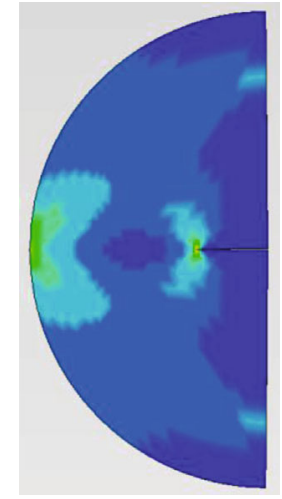

(c) $712 \mu \mathrm{s}$

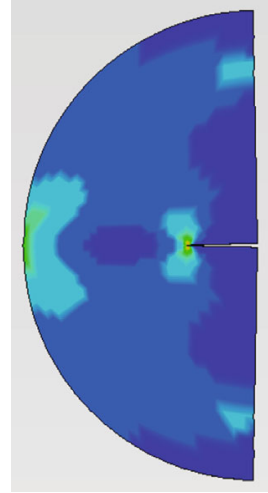

(d) $932 \mu \mathrm{s}$

FIGURE 11: Stress distribution in NSCBD specimens at different times.

At $520 \mu$ s, the stress distribution in the upper and lower symmetrical part of the NSCBD specimen is symmetric, and then the stress in the specimen changes dynamically, but it remains symmetrically distributed, as shown in Figure 11. Due to the short length of the loading direction of the NSCBD specimen, the stress wave propagates in the specimen for a short time history, so the time required to reach the stress balance is short.

\section{Stress Balance Analysis}

5.1. Stress Balance of Different Thicknesses of Specimens. Since the mesh of the specimen and the finite element model are both symmetrical, the stress of the symmetrical element at both ends of the specimen can be selected to determine the stress balance factor $\alpha_{k}$. In the thickness direction of both ends of the specimen, take the unit at a distance of $b(b=0$, $B / 8, B / 4$, and $3 B / 8$ ) from the center line of the thickness. As shown in Figure 12, the stress balance factor is calculated, and the time history curves of the stress balance factor of the five types of disc specimens are obtained as shown in Figure 13

Comparing Figures 13(a)-13(e), the change law is the same. When the stress wave is transmitted into the initial part of the specimen, the stress difference between the two ends is obvious, and $\alpha_{k}$ is large. During the process of stress wave reflection back and forth in the specimen, the stress in the specimen gradually became uniform, and $\alpha_{k}$ gradually decreased to near zero. The stress in the specimen changes continuously with time, and $\alpha_{k}$ also fluctuates within a certain range. Overall, the degree of stress balance of NSCBD is the best, followed by FBD, CSTFBD, BD, and CSTBD. Comparing the stress balance factor curves of the five specimens at different thicknesses, it is found that the difference of $\alpha_{k}$ curves of BD and FBD specimens at different thicknesses is very small, and the difference of $\alpha_{k}$ curves of CSTBD, CSTFBD, and NSCBD specimens is relatively obvious. The reason is that the prefabricated cracks lead to a large difference in the stress balance of the specimens at different thicknesses.

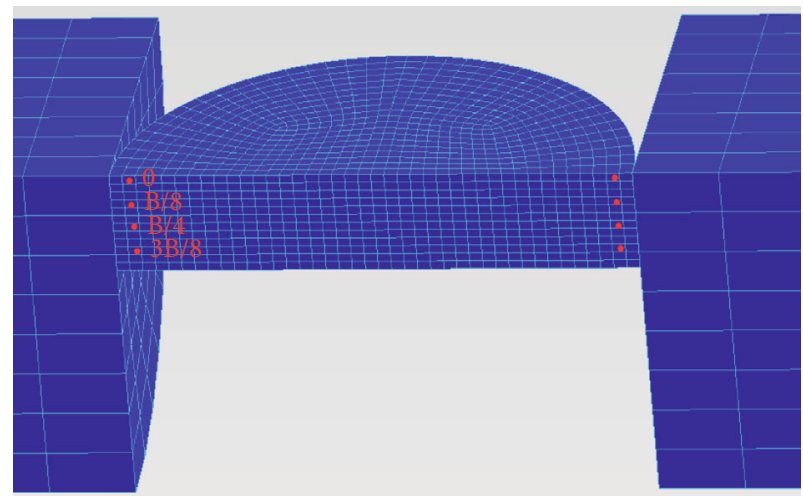

Figure 12: The unit selected at the end of the specimen.

5.2. Stress Balance on Loaded Ligaments. The literature $[49,50]$ suggests that energy waves will be dissipated during the propagation of stress waves in rocks. Liu et al. [51] proved that in the SHPB experiment, when the stress wave propagates through the rock specimen, its amplitude and frequency decrease. Therefore, it is not enough to analyze the stress balance at both ends of the specimen. It is also necessary to analyze the stress balance of different positions on the diameter ligament of the disc specimens. Symmetrical elements with distances from the center of the circle of $x(x=14 r / 15,4 r / 5,2 r / 3$, and $3 r / 5)$ were selected on the loaded diameter ligaments to analyze the stress balance. The results are shown in Figure 14.

As shown in Figures 14(a) and 14(b), in the BD and the FBD specimen, the stress balance at different locations on the loaded diameter ligament is almost identical. The CSTBD and CSTFBD specimens with prefabricated cracks have different balances at different positions on the loaded diameter ligament, of which CSTBD is more obvious. In Figure 14(c), as the value of $x$ decreases, $\alpha_{k}$ gradually increases, indicating that the stress balance gradually deteriorates from the end of the specimen to the crack tip. Comparing Figures 14(c) and 14(d), the difference in stress balance at different locations on the diameter ligament of the CSTFBD specimen is relatively small. Comparing 


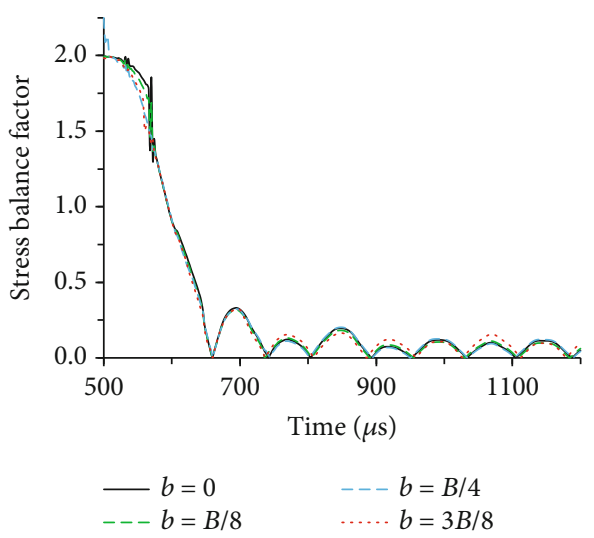

(a) BD specimen

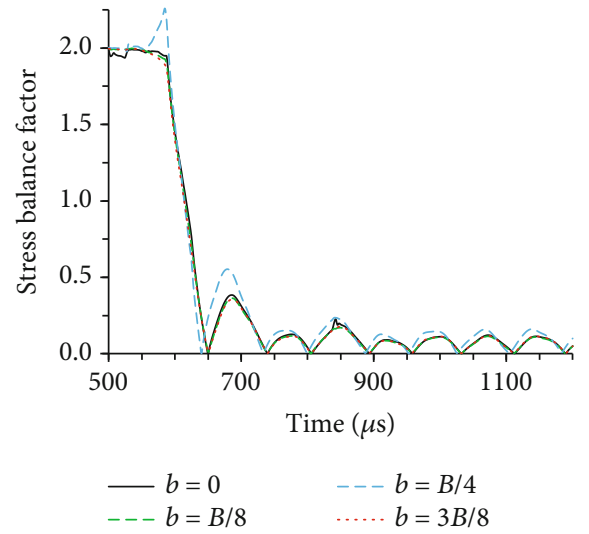

(c) CSTBD specimen

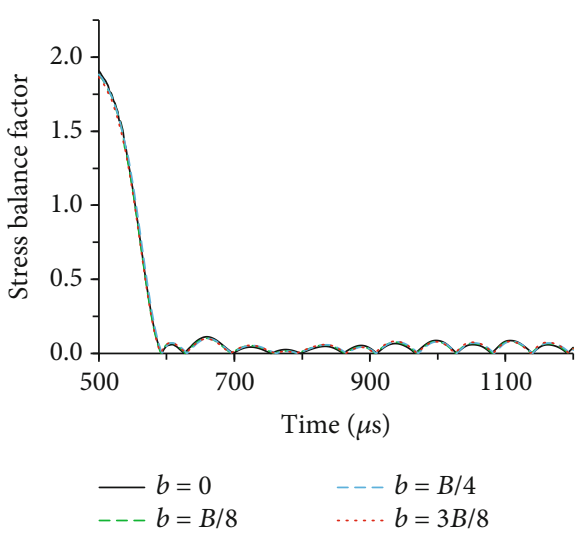

(b) FBD specimen

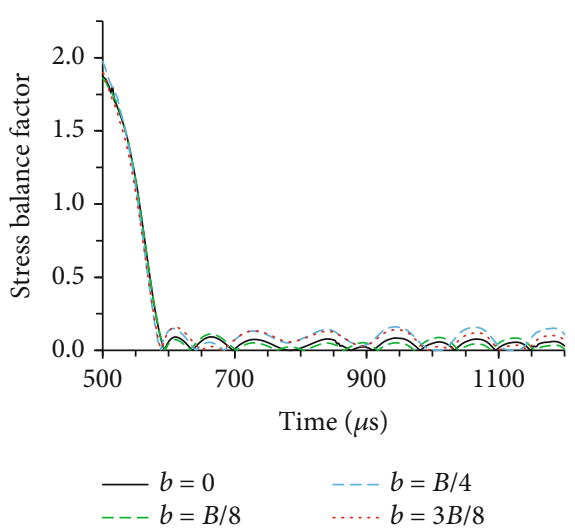

(d) CSTFBD specimen

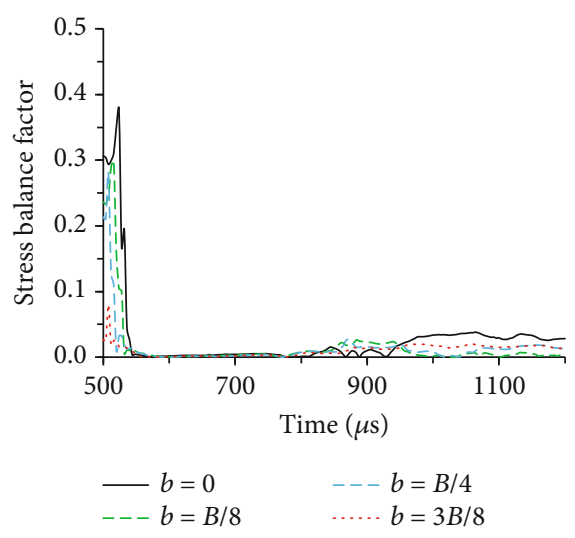

(e) NSCBD specimen

FIgURE 13: Stress balance factor curves for five types of disc specimens at different thicknesses.

Figure 9 with Figure 10, it can be seen that the contact area of the end portion of the CSTFBD specimen is large, and the transmission path of the transmitted wave in the specimen is wide, so that the influence by the crack is relatively small. However, the propagation path of the stress wave in the CSTBD specimen is mainly concentrated in the loading diameter region, so it is obviously affected by the crack. On the whole, the difference in stress balance on the diameter ligaments of the five types of disc specimens is negligible, so it is considered that the stress balance at both ends of the specimen can represent the stress balance of the entire specimen.
5.3. Overall Stress Balance of the Specimen. In order to analyze the stress balance of the whole specimen, the stress average value of the different thickness units at both ends of the specimen was substituted into formula (3), and the stress balance factors were calculated, and finally, the curve shown in Figure 15 was obtained. Table 3 lists the stress balance analysis results for the specimens of the five configurations.

The stress balance factor $\alpha_{k}$ of the BD specimen was reduced to 0.033 at $658 \mu \mathrm{s}$, reaching the stress equilibrium for the first time. From the stress wave into the specimen to the stress balance for $154 \mu \mathrm{s}$, we call it the equilibrium 

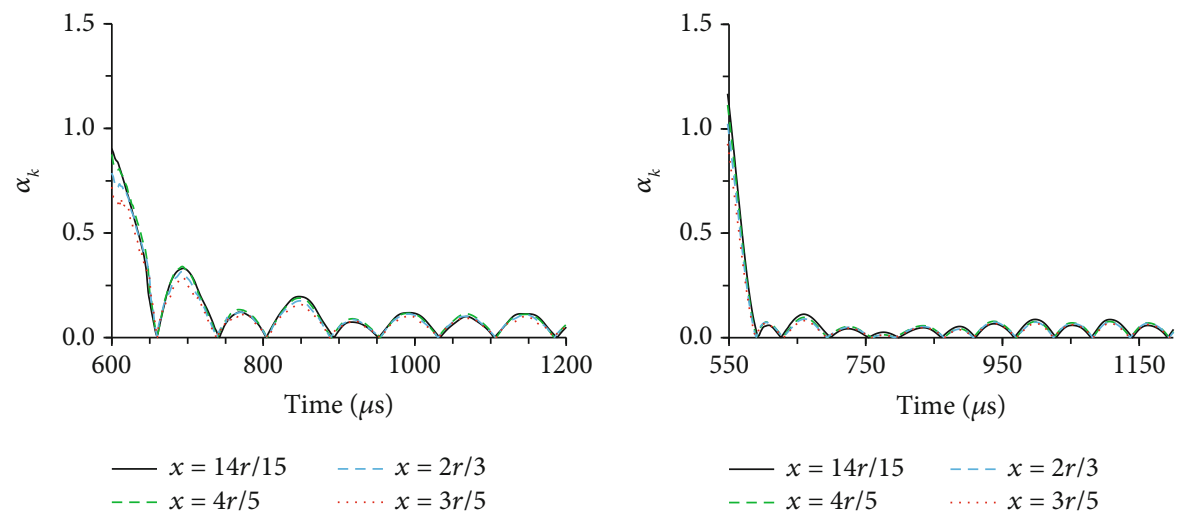

(a) BD specimen

(b) FBD specimen
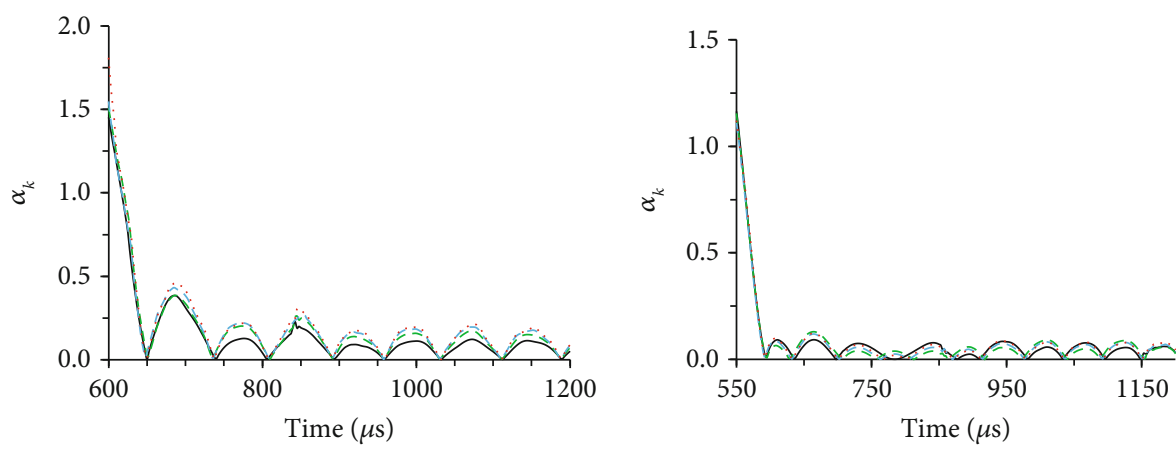

$$
\begin{aligned}
-x & =14 r / 15 \quad--x=2 r / 3 \\
--x & =4 r / 5
\end{aligned}
$$

(c) CSTBD specimen

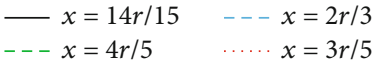

(d) CSTFBD specimen

FIGURE 14: Stress balance factor curve on the loaded diameter ligament of four types of disc specimens.

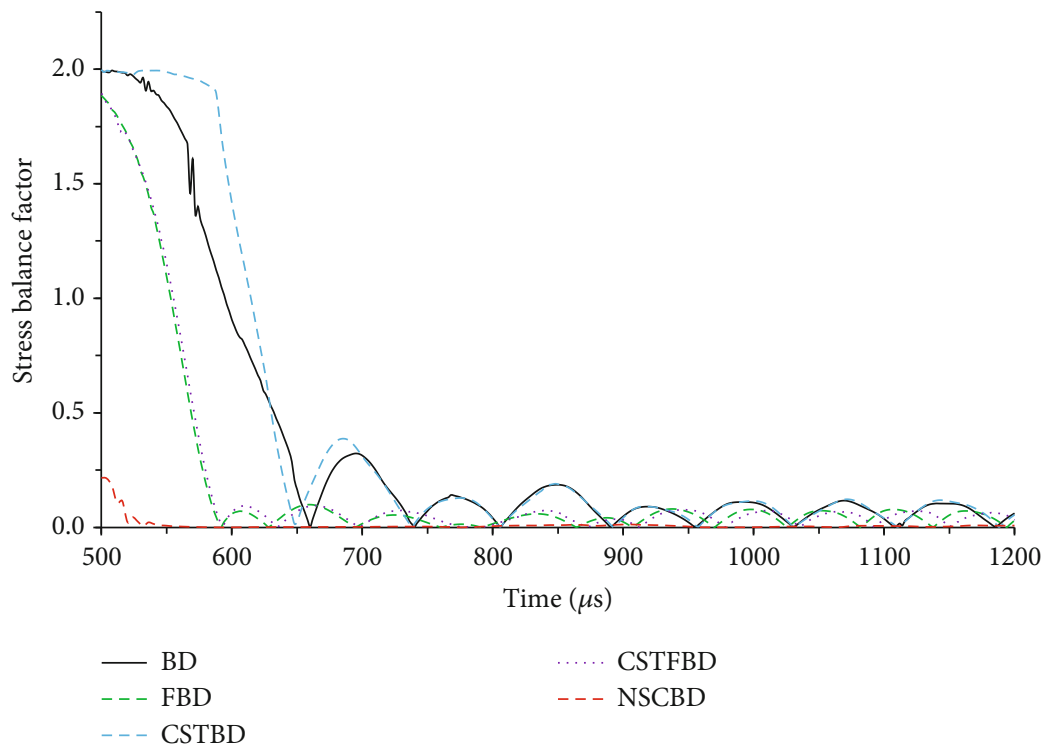

Figure 15: Stress balance factor time history curve of five configuration specimens.

transition period. After that, $\alpha_{k}$ fluctuates greatly with time, from $658 \mu$ s to $872 \mu$ s (the peak moment of the tensile stress of the central unit of the $\mathrm{BD}$ specimen), the maximum value of $\alpha_{k}$ is 0.322 , the minimum value is 0.0017 , and the average value is 0.143 . During this time, the equilibrium time accounts for $9.35 \%$. The time history curve of the stress balance factor of the CSTBD specimen is similar to that of the $\mathrm{BD}$ specimen. 
TABLE 3: Results of stress balance analysis of five configurations of disc specimens.

\begin{tabular}{lcccc}
\hline Model & Initial balance time $t_{1}(\mu \mathrm{s})$ & Peak tension time of specimen $t_{2}(\mu \mathrm{s})$ & Balanced transition period $(\mu \mathrm{s})$ & Mean value of $\alpha_{k}$ in $t_{1}-t_{2}$ \\
\hline BD & 658 & 872 & 154 & 0.143 \\
FBD & 588 & 904 & 84 & 0.038 \\
CSTBD & 648 & 890 & 144 & 0.147 \\
CSTFBD & 590 & 912 & 86 & 0.044 \\
NSCBD & 520 & 932 & 16 & 0.006 \\
\hline
\end{tabular}

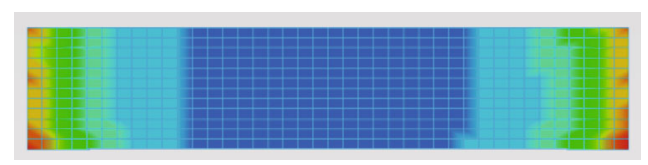

(a) BD specimen

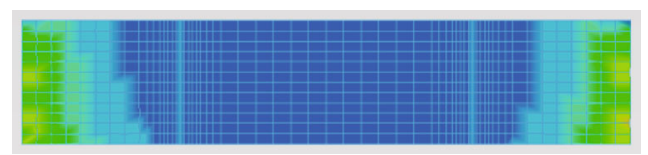

(c) CSTBD specimen

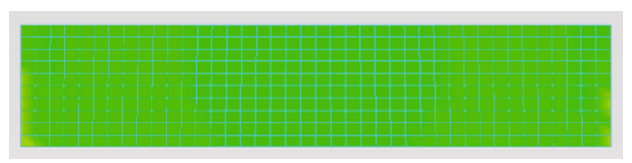

(b) FBD specimen

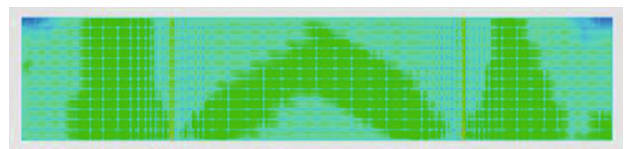

(d) CSTFBD specimen

FIGURE 16: Equivalent stress distribution on the section of the loaded diameter ligament.

The stress balance factor $\alpha_{k}$ of the FBD specimen was reduced to 0.045 at $588 \mu \mathrm{s}$, reaching the stress equilibrium for the first time. The stress balance transition period is only $84 \mu$ s. From $588 \mu$ s to $904 \mu$ s (peak time of tensile stress at the center of the FBD specimen), the maximum value of $\alpha_{k}$ is 0.099 , the minimum value is 0.0007 , and the average value is 0.038 . The specimen is in a stress equilibrium state within $42.4 \%$ of the time. The time history curve of the stress balance factor of the CSTFBD specimen is similar to that of the FBD specimen.

The stress balance factor $\alpha_{k}$ of the NSCBD specimen decreased to 0.023 at $520 \mu$ s, reaching the stress equilibrium for the first time. The stress balance transition period is only $16 \mu \mathrm{s}$. From $520 \mu \mathrm{s}$ to $932 \mu \mathrm{s}$ (the peak stress time of the crack tip unit of the NSCBD specimen), the $\alpha_{k}$ maximum is 0.045 , the minimum is 0.00001 , and the average is 0.0058 , and the specimen is always in equilibrium during this period.

\section{Influence of Different Factors on Dynamic Stress Balance of Disc Specimens}

From the above analysis, the stress balance of the different configuration specimens is different, and the stress balance of the specimen is related to the end condition, thickness, presence or absence of cracks, and loading mode of the specimen.

6.1. Influence of Specimen Thickness. The results in Section 5.1 have shown that the thickness of the specimen has effects on the stress balance, and the literature Sheng Zhang et al.[33] agrees. In order to analyze the reason, the stress distribution on the section of the ligament of the specimen loaded diameter is given, as shown in Figure 16. Comparing Figures $16(\mathrm{a})-16(\mathrm{~d})$, it is understood that the contact area of the end portion of the specimen is too small, and the pres- ence of the preformed crack causes uneven stress in the thickness direction of the disc specimen.

In order to quantitatively analyze the stress state at different thicknesses of the disc specimens, based on four specimens of BD, FBD, CSTBD, and CSTFBD, the stresses of all the units at $x=14 r / 15$ on the loaded diameter ligament were extracted. The maximum stress $\sigma_{\max }$, the minimum stress $\sigma_{\text {min }}$, and the average stress $\sigma_{\text {ave }}$ are analyzed as shown in Figure 17. The results show that the difference between $\sigma_{\max }$ and $\sigma_{\min }$ of BD specimen and FBD specimen is small, and the difference between $\sigma_{\max }$ and $\sigma_{\min }$ of CSTBD specimen and CSTFBD specimen is larger, and the difference increases first and then stabilizes with time.

Define the dispersion of stress distribution over the specimen thickness:

$$
\xi=\frac{\sigma_{\max }-\sigma_{\min }}{\sigma_{\text {ave }}}
$$

Therefore, the closer $\xi$ is to 0 , the more uniform the stress distribution on the cross-section. The stress distribution dispersion on the thickness of the BD, FBD, CSTBD, and CSTFBD specimens is calculated as $\xi 1, \xi 2, \xi 3$, and $\xi 4$, as shown in Figure 18.

Figure 18 shows that the CSTBD and CSTFBD specimens with prefabricated cracks have significantly higher $\xi$ values, and the FBD and CSTFBD specimens with platform have lower $\xi$ values than the BD and CSTBD specimens without the platform. It is revealed that the prefabricated cracks of the disc specimen and the absence of the platform at the end will increase the dispersion of the stress distribution on the disc thickness, and the influence of the prefabricated crack is more significant. Discrete stress on the thickness of the disc causes the specimen to exhibit different stress balances at different thicknesses. At the same time, for different 

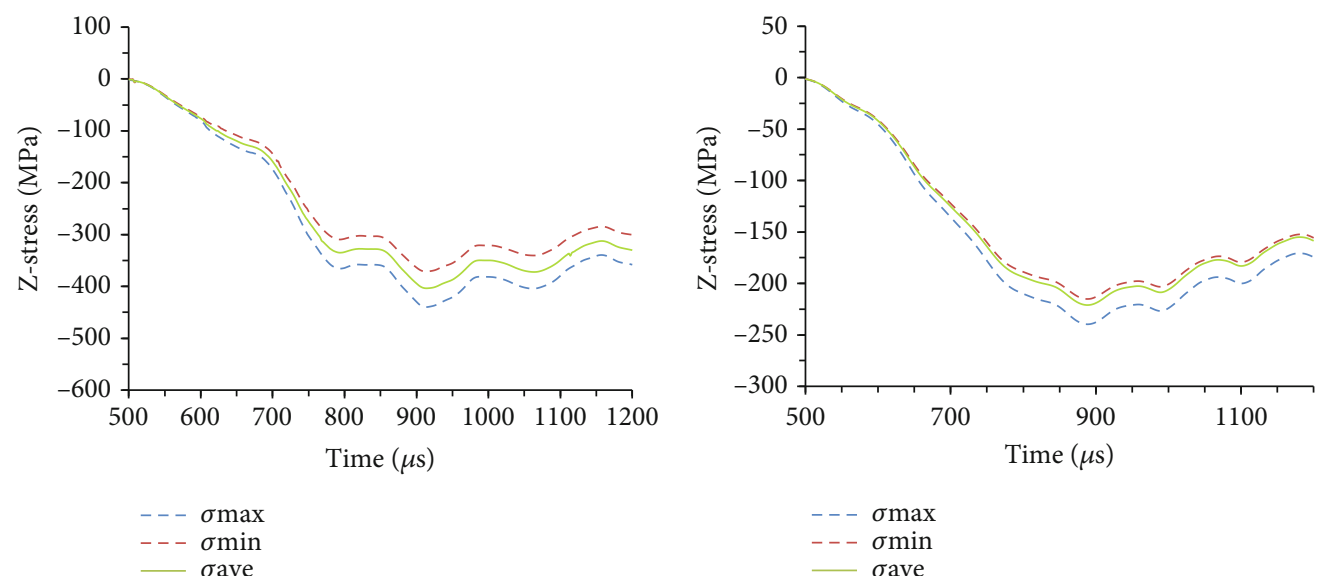

(a) BD specimen



(c) CSTBD specimen (b) FBD specimen

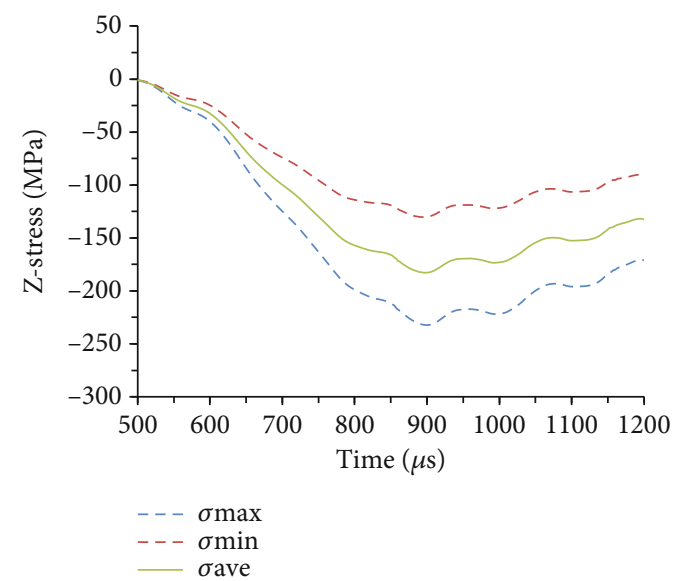

(d) CSTFBD specimen

FiguRE 17: Stress analysis at different thicknesses of the loaded ligament section.

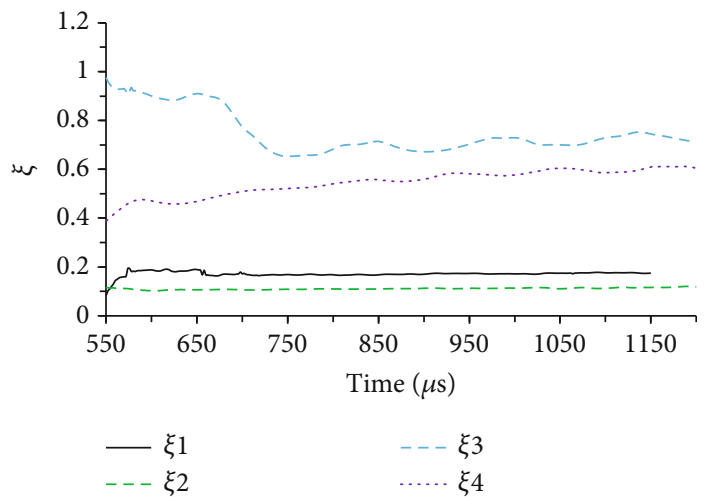

FIGURE 18: Stress distribution dispersion over the thickness of the specimens.

configuration disc, the location of the crack initiation will also be different.

6.2. Effect of the Ends of the Specimens. Unlike the cylindrical specimen, the contact end of the disc specimen with the pressure bar is small. In fact, the initial contact between the Brazilian disc and the bar is only almost a line, and the con- tact surface between the Brazilian disc and the bar is only a small platform. When a stress wave is transmitted from a large-section compression bar to a small-section specimen, the amplitude of the transmitted wave is stronger than the incident wave. The larger the ratio of the contact area of the pressure bar to the specimen, the larger the amplitude of the transmitted wave. When the contact surface is 0 , the transmitted wave amplitude is about twice that of the incident wave. This phenomenon may cause the incident end of the specimen to damage first and fail to reach a stress balance state.

The size of the cross-section of the disc specimen in the loading direction is constantly changing and can be regarded as a series of stepped microelement with strong discontinuity. When the stress wave passes through a discontinuous microelement, the amplitude of the stress wave will become the original $T_{A}$ times [9].

$$
T_{A}=\frac{2 A_{n}}{A_{n}+A_{n+1}} .
$$

In the formula, $A_{n}$ is the previous cross-section of the stepped cell, and $A_{n+1}$ is the last cross-section of the stepped 


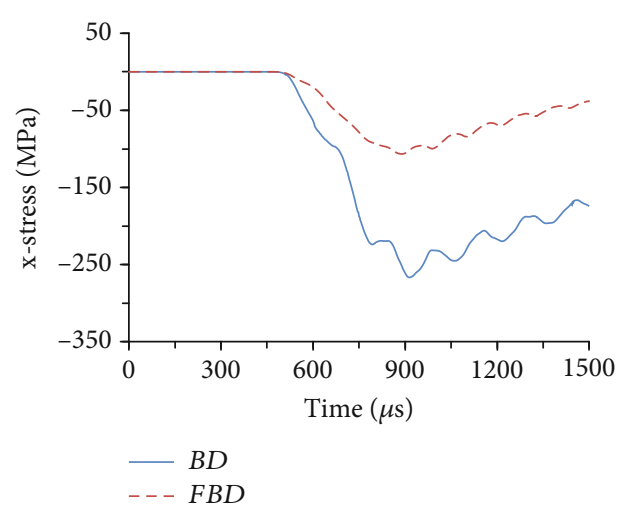

(a) $x$-direction stress

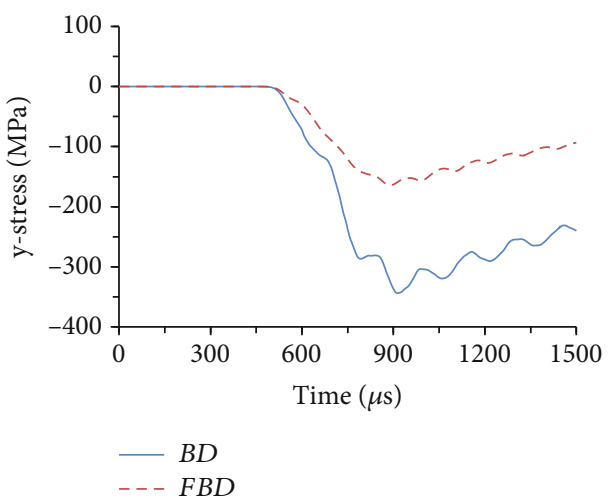

(b) $y$-direction stress

Figure 19: Nonaxial stresses at the center unit of the end of the two specimens.

cell. In the process of the compressive stress wave propagating from the incident end to the middle of the disc specimen, the cross-sectional area gradually becomes larger, so $T_{A}<1$, the amplitude of the stress wave gradually decreases. In the process of the compressive stress wave propagating from the middle position of the disc to the transmitting end of the specimen, $T_{A}>1$, the amplitude of the stress wave is gradually increased, and a reverse-stretching unloading wave is reflected and gradually increased. When the tensile stress wave intensity at the transmitting end of the specimen reaches a certain instantaneous fracture criterion, the fracture occurs, which affects the uniformity of the stress in the specimen.

Compare the $x$-direction stress and the $y$-direction stress at the end center unit of the $\mathrm{BD}$ and FBD specimens, as shown in Figure 19. The stress in the $x$ and $y$ directions of the central unit at the end of the $\mathrm{BD}$ specimen is 2.5 times and 2.1 times that of the FBD specimen, respectively, and is in the same magnitude as the stress in the $z$ direction. Therefore, the three-dimensional propagation of stress in the disc specimen cannot be ignored. Appropriately increasing the contact area of the end of the disc can reduce the non-onedimensional propagation of the stress, which is beneficial to the better balance of the disc specimen.

It can be seen from the stress cloud diagram analysis in Section 4.2 that the contact area of the end of the disc is too small, and the stress wave propagation path in the $z$ direction is mainly concentrated in the vicinity of the loading diameter. This will result in a slow stress balance of the specimens and a low degree of stress balance of the specimens.

Based on the above analysis, the contact area of the end of the disc specimen is small, which results in the stress concentration at the end of the specimen, the three-dimensional propagation of stress in the specimen, and the concentration of the stress wave propagation path in the $z$ direction. And the smaller the contact area of the end of the specimen, the more obvious this end effect is. These phenomena are not conducive to quickly reaching the state of stress equilibrium before failure of the specimen and are also not conducive to the degree of stress balance of the specimen.

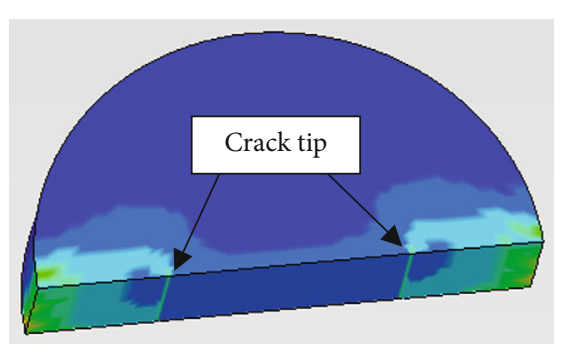

Figure 20: Three-dimensional distribution of stress in the CSTBD specimen.

6.3. Impact of the Existence of Cracks. The stress waves propagate theory through objects is based on the assumption of a uniform object. For the propagation of stress waves in infinitely heterogeneous rock masses, it is considered that when the wavelength of the elastic wave is much larger than the uneven scale in the rock, the rock mass can be regarded as a homogeneous object. However, compared with the disc specimen and the size of the prefabricated crack, the inertial effect of the crack cannot be ignored.

In the propagation path of the stress wave, wave loss and scattering occur at the crack tip, as shown in Figure 20. Scattering of the stress wave destroys the one-dimensional propagation of the stress wave, which in turn forms threedimensional propagation, thereby forming a hump-shaped stress distribution above the crack tip. And at the same time, the thickness effect is more obvious, and the stress balance in the area near the crack tip becomes worse. Figure 14(c) reflects this phenomenon. The closer to the crack tip on the loaded diameter ligament, the higher the stress balance factor, that is, the worse the stress balance is. In addition, the loss of compressive stress amplitude at the crack tip will affect the degree of stress balance at both ends of the specimen. As shown in Table 3, the average value of the CSTBD stress balance factor is higher than $\mathrm{BD}$, and the average value of the CSTFBD stress balance factor is higher than FBD.

6.4. Influence of Loading Method of Test Specimen. Just like other configuration specimens, the NSCBD specimen is affected by thickness, loading ends, and cracks, but its stress 


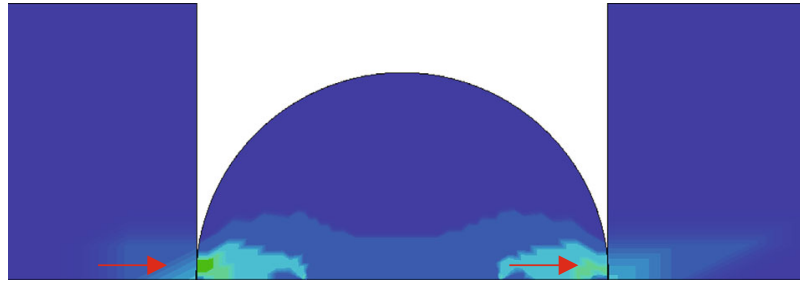

(a) Loading method of disc specimen

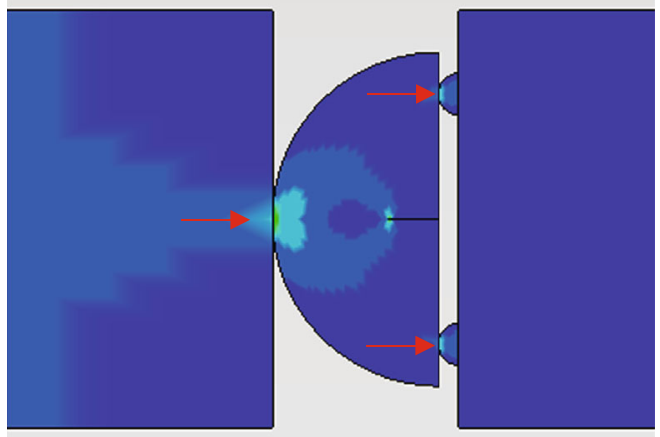

(b) Loading method of NSCBD specimen

FIGURE 21: Comparison of loading methods of BD and NSCBD specimens.

balance is the best. The main reason is that the specimen is stressed differently. As shown in Figure 21, the arrow symbols indicate the direction of stress propagation. The disc specimen has an entrance end and a transmission end, and its stress balance is measured according to the stress states of the entrance end and the transmission end. The direction of stress balance is the same as the loading direction, which requires the stress wave to be reflected back and forth in the specimen multiple times to achieve equilibrium. The NSCBD specimen has an entrance end, and two transmission ends are symmetrically distributed on both sides of the loading radius, and the balance is determined according to the stress state of the two transmission ends. The direction of stress equilibrium is perpendicular to the loading direction, and the propagation of stress waves in the specimen is symmetrical about the loading radius. Therefore, when the stress waves propagate to the transmitting end, the stress distribution is symmetrical, which greatly reduces the transition time of stress equilibrium.

\section{Discussions}

The interaction of the four influencing factors discussed in Section 6 affects the stress balance of the specimen. During the impact loading process, the stress concentration at the loading ends of the disc is obvious. The stress distribution in the test specimen is concentrated in the ligament area of the loading diameter, and the lateral stress is obvious, which is not conducive to the stress equilibrium of the specimen before failure. At the same time, the disc specimens have different stresses at different thicknesses, which results in different stress balances. The loss and divergence of the stress at the prefabricated crack tip affect the normal propagation of compressive stress waves. The thickness effect of the disc specimen is more obvious, resulting in a worse stress balance of the specimen, and the closer the position to the crack tip, the worse the stress balance is. Processing the platform at the end of the specimen can reduce the effects of stress concentration and thickness effects, and at the same time broaden the propagation path of the stress wave in the specimen, thereby reducing the impact of prefabricated cracks and achieving better stress balance. Under the condition that the contact area of the end of the specimen is small and there

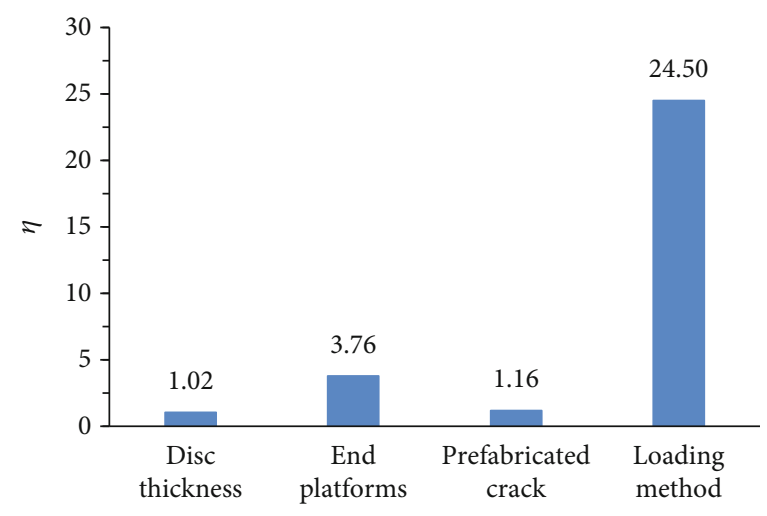

FIGURE 22: Influence factors of four factors.

are cracks in the specimen, the method of three-point bending loading can achieve a better stress balance.

In order to quantify and compare the influence of the four factors on the thickness of the disc, the end platform, the prefabricated cracks, and the loading method on the stress balance of the specimen, the stress balance factor $\eta$ was defined. Take the element on the loaded diameter ligament of the disc at the distance $x=14 r / 15$ from the center of the circle, calculate the average value of its stress balance factor and use it as the reference value $\alpha_{k 1}$. The influence factor of the disc end platform is the ratio of $\alpha_{k 1}$ of BD specimen to $\alpha_{k 1}$ of FBD specimen; the influence factor of prefabricated cracks is the ratio of $\alpha_{k 1}$ of CSTFBD specimen to $\alpha_{k 1}$ of FBD specimen; the influence factor of the loading method is the ratio of $\alpha_{k 1}$ of the CSTBD specimen to $\alpha_{k 1}$ of the NSCBD specimen; because the thicknesses of the five configurations are the same, the unevenness of the stress balance factor on the thickness of the discs is used to describe the influence of the thickness of the discs on the stress balance. Therefore, the influence factor of the disc thickness is the ratio of the maximum stress balance factor of the selected element to $\alpha_{k 1}$. The larger the value of $\eta$, the more obvious the influence of the factor on the stress balance of the specimen. Figure 22 shows the $\eta$ values of the four factors, reflecting that the degree of influence of these four factors on the stress balance is in descending order: loading method, end platform, prefabricated crack, and specimen thickness. 
Many literatures mention the classical three-wave method to verify the stress balance. Through simulation, it is found that, because the contact surface between the disc specimen and the compression bar is very small, the amplitude of the stress wave measured on the transmission bar is small, which makes it difficult to accurately capture it in the experiment, which is not conducive to verifying the stress balance using the three-wave method.

The model uses a disc with a diameter of $75 \mathrm{~mm}$ and a thickness of $30 \mathrm{~mm}$. The influence of the three-dimensional stress distribution of the test specimen on the stress balance is analyzed. However, if the disc thickness is increased or decreased, it will inevitably affect the stress distribution on the thickness of the disc specimens, and the law of the stress balance of the disc specimens will change with the thickness. If the specimen diameter increases, it will take more time for the stress wave to propagate from the incident end to the transmission end increases, and the influence of other factors will be amplified. In these cases, whether the specimen can reach the stress equilibrium before failure needs further research.

When the quasistatic method is used to determine the dynamic tensile strength, fracture toughness, and other parameters of the rock material, it is required that the incident end and the transmission end of the specimen achieve a force balance, so that the measured parameters are meaningful. Therefore, the stress balance is a necessary condition for using the quasistatic method to determine the dynamic mechanical parameters of the disc specimen. But for the experimental-numerical method, combined with experimental data and a three-dimensional full-bar model, to determine the dynamic fracture toughness of rock materials, there is no need to follow any static formula and it is not necessary to meet the stress balance.

\section{Conclusions}

A finite element numerical simulation method was used to establish a three-dimensional full-bar SHPB model. Five configuration types of disc specimens with a diameter of $75 \mathrm{~mm}$ and a thickness of $30 \mathrm{~mm}$ were used. The impact velocity of the special-shaped bullet was $5 \mathrm{~m} / \mathrm{s}$. Four factors are considered: the contact condition between the pressure bar and the specimen, the disc thickness, cracks, and loading method. By comparing the three-dimensional distribution characteristics of the stresses of five types of configuration disc specimens and analyzing the stress balance factors on the thickness of the specimen and the loaded diameter ligament, it is found that there is a certain difference in the stress balance of the discs of the five configurations. The main conclusions are as follows:

(1) Disc specimens with platforms at the ends are more conducive to achieving stress balance, and specimens containing cracks are not conducive to achieving stress balance. For specimens with cracks and no platform, three-point bending loading is more conducive to achieving stress balance
(2) According to the ease with which the stress balance is reached, the five configurations are ordered in order of NSCBD, FBD, CSTFBD, BD, and CSTBD. Among them, BD and CSTBD test specimens are not affected by end conditions and cracks and cannot achieve stress balance. The FBD and CSTFBD specimens can achieve stress balance due to the advantages of the platform at the end. The NSCBD specimens can more easily meet the stress balance due to the special loading method

(3) The disc specimen configuration does not meet the one-dimensional nature, and the internal stress distribution has three-dimensional characteristics. The existence of prefabricated cracks makes the propagation of stress waves more complicated. Therefore, the dynamic stress balance of disc specimens has strong limitations

Through the comparative analysis of the stress balance of the five types of disc test specimens, a pros and cons evaluation was made, revealing that SHPB stress balance has strict requirements for the disc test specimen configuration. In addition, it provides some references for selecting the appropriate specimen configuration and research methods. It is of great significance to accurately measure the dynamic fracture characteristics of rock masses.

\section{Data Availability}

The excel data supporting this research article is included in the supplementary documents.

\section{Conflicts of Interest}

The authors declare that they have no conflicts of interest.

\section{Acknowledgments}

This research was funded by the National Natural Science Foundation of China (no. 51674101).

\section{References}

[1] M. Z. Gao, S. Zhang, J. Li, and H. Y. Wang, "The dynamic failure mechanism of coal and gas outbursts and response mechanism of support structure," Thermal Science, vol. 23, Suppl. 3, pp. 867-S875, 2019.

[2] M. Z. Gao, Z. L. Zhang, Y. Xiangang, C. Xu, Q. Liu, and H. L. Chen, "The location optimum and permeability-enhancing effect of a low-level shield rock roadway," Rock Mechanics and Rock Engineering, vol. 51, no. 9, pp. 2935-2948, 2018.

[3] Z. J. Wen, S. L. Jing, Y. J. Jiang et al., "Study of the fracture law of overlying strata under water based on the flow- stressdamage model," Geofluids, vol. 2019, Article ID 3161852, 12 pages, 2019.

[4] Z. J. Wen, X. Wang, Y. L. Tan, H. L. Zhang, W. P. Huang, and Q. H. Li, "A study of rockburst hazard evaluation method in coal mine," Shock and Vibration, vol. 2016, Article ID 8740868, 9 pages, 2016. 
[5] X. Wang, Z. J. Wen, Y. J. Jiang, and H. Huang, "Experimental study on mechanical and acoustic emission characteristics of rock-like material under non-uniformly distributed loads," Rock Mechanics and Rock Engineering, vol. 51, no. 3, pp. 729-745, 2018.

[6] M. Z. Gao, R. Zhang, J. Xie, G. Y. Peng, B. Yu, and P. G. Ranjith, "Field experiments on fracture evolution and correlations between connectivity and abutment pressure under top coal caving conditions," International Journal of Rock Mechanics and Mining Sciences, vol. 111, pp. 84-93, 2018.

[7] S. S. Hu, L. L. Wang, L. Song, and L. Zhang, "Review of the development of Hopkinson pressure bar technology in China," Explosion and Shock Waves, vol. 34, no. 6, pp. 641657, 2014.

[8] K. W. Xia and W. Yao, "Dynamic rock tests using split Hopkinson (Kolsky) bar system - a review," Journal of Rock Mechanics and Geotechnical Engineering, vol. 7, no. 1, pp. 27-59, 2015.

[9] L. L. Wang, Foundation of Stress Waves, National Defense Industry Press, Beijing, China, 2005.

[10] F. Dai, S. Huang, K. W. Xia, and Z. Y. Tan, "Some fundamental issues in dynamic compression and tension tests of rocks using split Hopkinson pressure bar," Rock Mechanics and Rock Engineering, vol. 43, no. 6, pp. 657-666, 2010.

[11] D. H. Ai, Y. C. Zhao, B. J. Xie, and C. W. Li, "Experimental study of fracture characterizations of rocks under dynamic tension test with image processing," Shock and Vibration, vol. 2019, Article ID 6352609, 14 pages, 2019.

[12] X. Y. Fang and J. Y. Xu, "A modified overstress model to simulate dynamic split tensile tests and its experimental validation," Rock Mechanics and Rock Engineering, vol. 49, no. 9, pp. 3823-3828, 2016.

[13] Q. Z. Wang, J. R. Yang, C. G. Zhang et al., "Determination of dynamic crack initiation and propagation toughness of a rock using a hybrid experimental-numerical approach," Journal of Engineering Mechanics, vol. 142, no. 12, article 04016097, 2016.

[14] T. B. Yin, S. S. Zhang, X. B. Li, and L. Bai, "A numerical estimate method of dynamic fracture initiation toughness of rock under high temperature," Engineering Fracture Mechanics, vol. 204, pp. 87-102, 2018.

[15] H. Fan, S. Zhang, and Q. Z. Wang, "Determination of dynamic initiate toughness of concrete using cracked straight-through flattened Brazilian disc," Journal of Hydraulic Engineering, vol. 41, no. 10, pp. 1234-1240, 2010.

[16] S. J. Zhao and Q. Zhang, "Dynamic crack propagation and fracture behavior of pre-cracked specimens under impact loading by split Hopkinson pressure bar," Advances in Materials Science and Engineering, vol. 2019, Article ID 2383861, 11 pages, 2019.

[17] S. Zhang and Q. Z. Wang, "Method for determination of dynamic fracture toughness of rock using holed-cracked flattened disc specimen," Chinese Journal of Geotechnical Engineering, vol. 28, no. 6, pp. 723-728, 2010.

[18] S. Zhang, Y. Q. Lu, and Q. Z. Wang, "P-CCNBD specimen used for measuring dynamic fracture propagation toughness of rock and observing dynamic arrest phenomenon," Rock and Soil Mechanics, vol. 38, no. 11, pp. 3095-3105, 2017.

[19] M. D. Wei, F. Dai, N. W. Xu, and T. Zhao, "Experimental and numerical investigation of cracked chevron notched Brazilian disc specimen for fracture toughness testing of rock," Fatigue
\& Fracture of Engineering Materials \& Structures, vol. 41, no. 1, pp. 197-211, 2018.

[20] R. Chen, K. Xia, F. Dai, F. Lu, and S. N. Luo, "Determination of dynamic fracture parameters using a semi-circular bend technique in split Hopkinson pressure bar testing," Engineering Fracture Mechanics, vol. 76, no. 9, pp. 1268-1276, 2009.

[21] Y. Wang, "Rock dynamic fracture characteristics based on NSCB impact method," Shock and Vibration, vol. 2018, Article ID 3105384, 13 pages, 2018.

[22] S. Zhang, L. F. Wang, and M. Z. Gao, "Experimental and numerical study of the influence of prefabricated crack width on the fracture toughness of NSCB specimens," Rock Mechanics and Rock Engineering, vol. 53, no. 11, pp. 51335154, 2020.

[23] H. du, F. Dai, K. W. Xia, N. W. Xu, and Y. Xu, "Numerical investigation on the dynamic progressive fracture mechanism of cracked chevron notched semi-circular bend specimens in split Hopkinson pressure bar tests," Engineering Fracture Mechanics, vol. 184, pp. 202-217, 2017.

[24] M. D. Wei, F. Dai, Y. Liu, N. W. Xu, and T. Zhao, “An experimental and theoretical comparison of CCNBD and CCNSCB specimens for determining mode I fracture toughness of rocks," Fatigue \& Fracture of Engineering Materials \& Structures, vol. 41, no. 5, pp. 1002-1018, 2018.

[25] Q. Zhang and J. Zhao, "A review of dynamic experimental techniques and mechanical behaviour of rock materials," Rock Mechanics and Rock Engineering, vol. 47, no. 4, pp. 1411-1478, 2014.

[26] K. Man and H. W. Zhou, "Dynamic force balance analysis of SHPB system," Metal Mine, vol. 39, no. 11, pp. 27-30, 2014.

[27] D. J. Frew, M. J. Forrestal, and W. Chen, "Pulse shaping techniques for testing brittle materials with a split Hopkinson pressure bar," Experimental Mechanics, vol. 42, no. 1, pp. 93106, 2002.

[28] T. S. Lok, X. B. Li, D. Liu, and P. J. Zhao, "Testing and response of large diameter brittle materials subjected to high strain rate," Journal of Materials in Civil Engineering, vol. 14, no. 3, pp. 262-269, 2002.

[29] X. B. Li, Y. Zou, and Z. L. Zhou, "Numerical simulation of the rock SHPB test with a special shape striker based on the discrete element method," Rock Mechanics, vol. 47, no. 5, pp. 1693-1709, 2014.

[30] Z. L. Zhou, X. B. Li, and X. M. Yan, "Loading condition for specimen deformation at constant strain rate in SHPB test of rocks," Chinese Journal of Rock Mechanics and Engineering, vol. 28, no. 12, pp. 2445-2452, 2009.

[31] Q. Ping, Q. Y. Ma, J. S. Zhang, P. Yuan, and B. S. Chen, "SHPB test and analysis of dynamic tensile performance of sandstone under high strain rate," Chinese Journal of Rock Mechanics and Engineering, vol. 31, no. S1, pp. 3363-3369, 2012.

[32] W. Li, H. P. Xie, and Q. Z. Wang, “An experimental study for the dynamic split tension of marble disc using SHPB," Explosion and Shock Waves, vol. 26, no. 1, pp. 12-20, 2006.

[33] S. Zhang, X. W. Li, and X. H. Yang, "Dynamic stress equilibrium of disc specimen under linear increase impact loading," The Chinese Journal of Nonferrous Metals, vol. 24, no. 1, pp. 75-81, 2014.

[34] Q. Z. Wang, J. R. Yang, C. G. Zhang et al., "Sequential determination of dynamic initiation and propagation toughness of rock using an experimental-numerical-analytical method," Engineering Fracture Mechanics, vol. 141, pp. 78-94, 2015. 
[35] T. B. Yin, L. Bai, X. Li, X. Li, and S. Zhang, "Effect of thermal treatment on the mode I fracture toughness of granite under dynamic and static coupling load," Engineering Fracture Mechanics, vol. 199, pp. 143-158, 2018.

[36] F. Dai, R. Chen, and K. W. Xia, "A semi-circular bend technique for determining dynamic fracture toughness," Experimental Mechanics, vol. 50, no. 6, pp. 783-791, 2010.

[37] Q. B. Zhang and J. Zhao, "Determination of mechanical properties and full-field strain measurements of rock material under dynamic loads," International Journal of Rock Mechanics \& Mining Sciences, vol. 60, pp. 423-439, 2013.

[38] S. Zhang, X. W. Li, and X. H. Yang, "Influence of different dynamic load calculating methods on rock dynamic fracture toughness test," Rock and Soil Mechanics, vol. 34, no. 9, pp. 2721-2726, 2013.

[39] S. Zhang and X. W. Li, "Influence of diameter of center holes on measured values of dynamic fracture toughness of rock," Chinese Journal of Rock Mechanics and Engineering, vol. 34, no. 8, pp. 1660-1666, 2015.

[40] D. W. Xiao and S. S. Hu, "Study of two-dimensional effect on SHPB experiment," Explosion and Shock Waves, vol. 27, no. 1, pp. 87-90, 2007.

[41] S. Zhang and X. H. Yang, "Influence of determining rock dynamic fracture toughness by disc specimens with inconsistent crack fracture," Chinese Journal of Underground Space and Engineering, vol. 10, no. 5, pp. 1101-1108, 2014.

[42] R. J. Christensen, S. R. Swanson, and W. S. Brown, "SplitHopkinson-bar tests on rock under confining pressure," Experimental Mechanics, vol. 12, no. 11, pp. 508-513, 1972.

[43] S. Luo and F. Q. Gong, "Experimental and numerical analyses of the rational loading waveform in SHPB test for rock materials," Advances in Civil Engineering, vol. 2018, Article ID 3967643, 13 pages, 2018.

[44] Y. X. Zhou, K. W. Xia, X. B. Li et al., "Suggested methods for determining the dynamic strength parameters and mode-I fracture toughness of rock materials," International Journal of Rock Mechanics and Mining Sciences, vol. 49, pp. 105-112, 2012.

[45] L. M. Yang and V. P. W. Shim, "An analysis of stress uniformity in split Hopkinson bar test specimens," International Journal of Impact Engineering, vol. 31, no. 2, pp. 129-150, 2005.

[46] Y. J. Mao and Y. L. Li, "Axial stress uniformity in specimens of SHPB tests," Explosion and Shock Waves, vol. 28, no. 5, pp. 448-454, 2008.

[47] K. Peng, K. Gao, J. Liu et al., "Experimental and numerical evaluation of rock dynamic test with split- Hopkinson pressure bar," Advances in Materials Science and Engineering, vol. 2017, Article ID 2048591, 12 pages, 2017.

[48] G. Ravichandran and G. Subhash, "Critical appraisal of limiting strain rates for compression testing of ceramics in a split Hopkinson pressure bar," Journal of the American Ceramic Society, vol. 77, no. 1, pp. 263-267, 1994.

[49] M. Li, X. B. Mao, A. H. Lu et al., "Effect of specimen size on energy dissipation characteristics of red sandstone under high strain rate," International Journal of Mining Science and Technology, vol. 24, no. 2, pp. 151-156, 2014.
[50] J. C. Li, L. F. Rong, H. B. Li, and S. N. Hong, “An SHPB test study on stress wave energy attenuation in jointed rock masses," Rock Mechanics and Rock Engineering, vol. 52, no. 2, pp. 403-420, 2019.

[51] X. L. Liu, J. H. Cui, X. B. Li, and Z. Liu, "Study on attenuation characteristics of elastic wave in different types of rocks," Chinese Journal of Underground Space and Engineering, vol. 37, no. S1, pp. 3223-3230, 2018. 